\title{
Levee reliability analyses for various flood return periods - a case study in southern Taiwan
}

\author{
W.-C. Huang ${ }^{1}$, H.-W. Yu ${ }^{1}$, and M.-C. Weng ${ }^{2}$ \\ ${ }^{1}$ Department of Civil Engineering, National Central University, Taoyuan, Taiwan \\ ${ }^{2}$ Department of Civil and Environmental Engineering, National University of Kaohsiung, Kaohsiung, Taiwan \\ Correspondence to: W.-C. Huang (wenchaoh@ncu.edu.tw)
}

Received: 30 October 2014 - Published in Nat. Hazards Earth Syst. Sci. Discuss.: 19 January 2015

Revised: 5 April 2015 - Accepted: 8 April 2015 - Published: 24 April 2015

\begin{abstract}
In recent years, heavy rainfall conditions have caused disasters around the world. To prevent losses by floods, levees have often been constructed in inundationprone areas. This study performed reliability analyses for the Chiuliao First Levee in southern Taiwan. The failure-related parameters were the water level, the scouring depth, and the in situ friction angle. Three major failure mechanisms were considered: the slope sliding failure of the levee and the sliding and overturning failures of the retaining wall. When the variability of the in situ friction angle and the scouring depth are considered for various flood return periods, the variations of the factor of safety for the different failure mechanisms show that the retaining wall sliding and overturning failures are more sensitive to the change of the friction angle. When the flood return period is greater than 2 years, the levee could fail with slope sliding for all values of the water level difference. The results of levee stability analysis considering the variability of different parameters could aid engineers in designing the levee cross sections, especially with potential failure mechanisms in mind.
\end{abstract}

\section{Introduction}

Taiwan is in a subtropical area, so disastrous weather conditions due to typhoons are inevitable during the summer. Precipitation in the range of 2500-3000 $\mathrm{mm}_{\text {year }}{ }^{-1}$ has been recorded in the mountainous areas of southern Taiwan and this enormous rainfall can cause floods. If levees are not designed and constructed properly, the outcome can be disastrous. In general, there are several possible failure mechanisms of a levee system during floods: (1) overflowing and wave overtopping, (2) scouring of the foundation, (3) seepage/piping of the levee body, and (4) foundation sliding or slope sliding of the levee (Ojha et al., 2001; Vrijling et al., 2011; Dos Santos et al., 2011; Zhang et al., 2013). These mechanisms are influenced by the levee's geometrical configuration, the hydraulic conditions (e.g., water level and seepage conditions), and the engineering properties of the levee backfill material and the in situ soils.

Overflowing occurs when the flood water level exceeds the design capacity of the levee and flows over the structure, and it is a common failure mechanism. (Dou et al., 2014) During Hurricane Katrina, the levee system surrounding New Orleans experienced catastrophic overflowing, which was possibly due to shoaling and resulted in the inundation of approximately $80 \%$ of the city. Many researchers have studied the stability of levees under overflowing (Seed et al., 2008a, b; Xu et al., 2012). The consequence of overflowing for the flood wall in suburban areas of New Orleans, USA, was the gap formed between the flood wall and the canal-side backfill. The built-up water pressure against the flood wall pushed over the flood wall and thus caused inundation around the navigation canal (Brandon et al., 2008; Duncan et al., 2008). Besides, overflowing for the levee can also erode the backfill at the protected side (also known as a landside; "protected side" is used throughout the text hereafter) of the levee, leading to a loss of support from the backfill material at the protected side of the levee (Briaud et al., 2008). Wave overtopping was considered as a dynamic failure mechanism and therefore it is not the main focus in this study.

Piping and inside levee erosion are also common failure mechanisms for levees (El Shamy and Aydin, 2008; Rieg- 
ger et al., 2009). During Hurricane Katrina, some part of the city canal flood wall did not experience overflowing, but the surrounding areas were still inundated. Site investigation and analysis results have shown that seepage-induced piping or heaving is also one of the possible failure mechanisms. The major reason for the piping and heaving to occur is insufficient subsurface exploration (IPET, 2007). For seepage and piping inside the levee or embankment body, Polemio and Lollino (2011) also employed a case study in Italy to define the factors affecting seepage-induced failure due to flood.

For levee slope sliding failure or foundation failure, Zhang et al. (2013) analyzed the levee in the Pearl River delta under the above failure mechanisms. However, based on historical records, the local scouring of the flood side (also known as waterside; "flood side" is used throughout the text hereafter) backfill was not serious and thus was not considered in the study. Huang et al. (2014) also examined the levee foundation stability with respect to sliding and overturning failure. It was found that the sliding of the levee foundation might be a possible failure mechanism under certain water level conditions. Although shallow slope sliding failure is also one of the possible failure mechanisms for levees, we have considered the full levee sliding as one of the failure mechanisms in this study because shallow slope sliding may only happen when the superficial cover material was not constructed or compacted well. In our analyses, shallow sliding failure can only occur when levee cover material with low shear strength exists, which is not the actual condition in the study levee.

In this study, we performed a more in-depth levee stability analysis, considering possible failure mechanisms and variability of parameters. The considered failure mechanisms are slope sliding stability and foundation stability under different conditions. The rest of the possible failure mechanisms as mentioned above were ruled out based on interviewing reports from local residents and relevant analysis. Furthermore, based on the experience and lessons learned from Hurricane Katrina in New Orleans, it was suggested that risk-based analyses and designs are needed to consider parameter variability for possible extreme weather events (Sills et al., 2008; van Gelder et al., 2008). Therefore, the analyses in this study consider the responses of the case levee to the variation in the flood return period and the parameters. By considering the variability in parameters such as the in situ friction angle, the responses of levees to various situations can be considered and incorporated into the engineering design of future levees. In this paper, we demonstrate this approach by performing reliability analyses for Chiuliao First Levee. The goal of this study is therefore to assess the stability of Chiuliao First Levee for various return periods, with the aim of providing insights into the design of levees. We hope that the proposed approach in this study can ensure levee stability under different flood return periods and provide guidance for reliability analyses for levees under different scenarios.

\section{Descriptions of Chiuliao First Levee}

On 8 August 2009, Typhoon Morakot invaded southern Taiwan and caused significant loss of life and property (Lin et al., 2011; Wu et al., 2011; Weng et al., 2011; Huang et al., 2014). Many levees and revetments in southern Taiwan were damaged during this event, and the river basin suffered severe flood disasters. In particular, the failed levees along Laonong River have been investigated thoroughly due to the large population that resides along this river. Of the levee breaches along Laonong River, the most serious occurred at the Chiuliao First Levee, which is located in Kaoshu village in Pingtung County, as shown in Fig. 1. This levee was built on the left river bank near the confluence of Laonong River and its branch, Chokuo River. During Typhoon Morakot, Chiuliao First Levee broke apart, providing an opening for water to invade the protected side of the structure. This event drew significant public attention to the issue of levee safety, especially for levees in the suburban areas.

\subsection{Levees along Laonong River and the site conditions}

Laonong River basin is in the southern part of Taiwan and it is a tributary of Gaoping River. The length of Laonong River is approximately $133 \mathrm{~km}$. During Typhoon Morakot, the levees along Laonong River experienced catastrophic breaches. Of the eight levees (Gueishan Levee, Chiuliao First and Second levees, Leegang Levee, Dongjengshin Levee, Tsailiao Levee, Toocool Levee, and Shinshin Levee; the total length of the above levees is approximately $23 \mathrm{~km}$ ) along Laonong River, four experienced catastrophic breaches, as shown in Table 1. The total breached length was about $1.5 \mathrm{~km}$ (see Table 1 for more details). Of these failed levees, Chiuliao First Levee and Shinshin Levee were washed away completely by the floods during Typhoon Morakot.

To analyze the stability of these levees, the site conditions along Laonong River, especially near the failed levees, must be obtained. In this study, site conditions were obtained by performing borehole measurements at bridges near the studied levees. Along Laonong River, the soil layers consist mostly of gravel to a depth of approximately $20 \mathrm{~m}$.

The bridge near Chiuliao First Levee is Dajin bridge. Huang et al. (2014) analyzed borehole information from Dajin bridge to determine the in situ subsurface profile. It was found that the friction angles of the gravel layer are in the range of about $37-45^{\circ}$. Chiuliao First Levee is located on Laonong River in section no. 14. The average particle size of the river bed material in this section is approximately $60.55 \mathrm{~mm}$. The particle size analysis results for the river section along Laonong River between its confluences with Chokuo River and Kaoping River show that the in situ riverbed material is well-graded gravel according to the United Soil Classification System. 


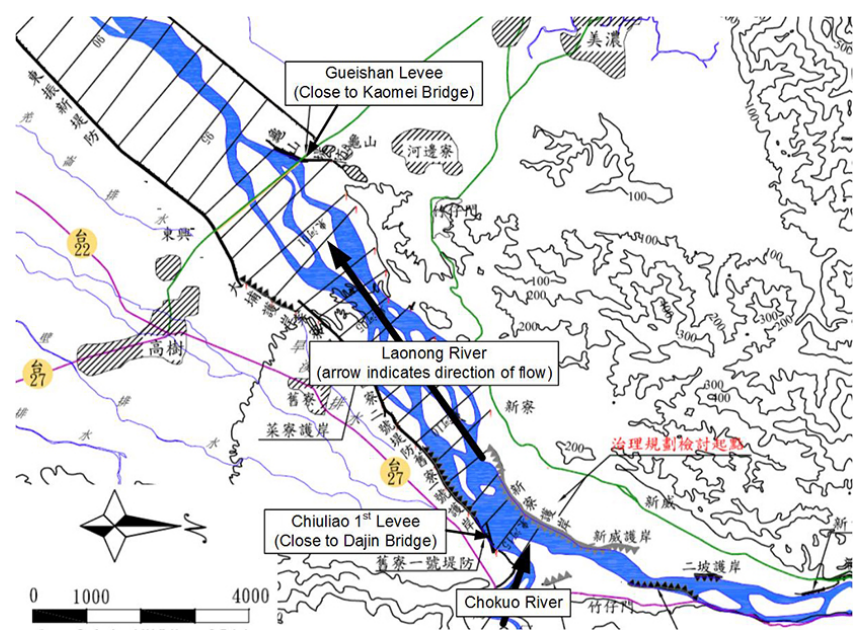

Figure 1. Locations of Chiuliao First Levee, Gueishan Levee, Laonong River, and Chokuo River.

Table 1. Flood-induced levee failures along Laonong River during Typhoon Morakot in 2009 (modified from Liu et al., 2009, and Huang et al., 2014).

\begin{tabular}{lll}
\hline No. & Levee/total length $(\mathrm{m})$ & Failure condition \\
\hline 1 & Gueishan Levee/1328 & Breached for about $200 \mathrm{~m}$ \\
2 & Chiuliao Second Levee/815 & Breached for about 270 m \\
3 & Chiuliao First Levee/648 & $\begin{array}{l}\text { Total collapse } \\
\text { (breached for } 648 \mathrm{~m} \text { ) }\end{array}$ \\
4 & Shinshin Levee/440 & $\begin{array}{l}\text { Total collapse } \\
\text { (breached for } 440 \mathrm{~m} \text { ) }\end{array}$ \\
\hline
\end{tabular}

\subsection{Design of the levee}

In addition to the site conditions close to the levee, we also examined the design cross section of Chiuliao First Levee before Typhoon Morakot, as shown in Fig. 2. This levee was a gravity-type earthen levee with a height of $10.7 \mathrm{~m}$. The foundation of the levee was laid on the surface of the in situ gravel layer, with $1.5 \mathrm{~m}$ thick backfill on the flood side of the levee. In addition, another layer of rockfill (tetrapods) was placed on top of the backfill layer to prevent scouring of the backfill.

\section{Research approach}

\subsection{Levee failure mechanisms}

As mentioned above, possible levee failure mechanisms include (1) overflowing and wave overtopping, (2) scouring of the foundation, (3) seepage/piping of the levee body, and (4) sliding of the foundation and levee slope sliding. However, overflowing was not the main failure mechanism in the case of the breach of Chiuliao First Levee during Typhoon Morakot. According to the field investigation and the reports

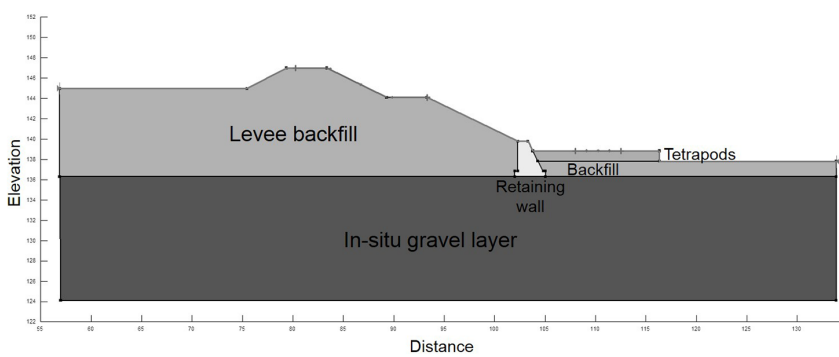

Figure 2. Simplified cross section of Chiuliao First Levee before Typhoon Morakot (modified from Huang et al., 2014).

of eyewitnesses ( $\mathrm{Li}$ et al., 2009; Chang, 2012), no evidence of overflowing was found on the protected side of the levee, such as flow traces or inundation. As mentioned previously, wave overtopping was not considered in this study. For levee failure mechanisms, it has been shown that the Chiuliao First Levee could fail due to slope sliding and retaining wall sliding failure when the flood started to recede from the top of levee (Huang et al., 2014). The timing of the levee failure is consistent with the eyewitness reports. Preliminary analyses of the seepage inside the levee also showed that the exit hydraulic gradient is much less than the critical hydraulic gradient. Therefore we focused on the three major failure mechanisms discussed above (slope failure, retaining wall sliding, and overturning failure), which are related to the three parameters discussed in the next section.

In summary, the following failure mechanisms were considered in this study:

- loss of slope stability of the levee under steady state seepage conditions

- loss of retaining wall stability (due to sliding and overturning failures) under steady state seepage conditions; the bearing capacity failure of the retaining wall foundation is unlikely given that the in situ friction angle is greater than $35^{\circ}$ and so was not analyzed in this study.

\subsection{Research method}

Based on the analyses performed in Huang et al. (2014), a limited number of scenarios (limited scouring depths (SD) and water levels) were analyzed to understand possible levee failure mechanisms. For the purpose of risk assessment (as discussed later in the text), a more in-depth analysis of levee stability with respect to variations of the parameters is required. First, we analyzed the stability of the slope and retaining wall of the Chiuliao First Levee within possible range of parameter values. The drainage and clog conditions on the protected and flood sides of the levee determine whether their water levels are the same. A difference between these two water levels results in steady seepage conditions in the levee, because the backfill material is mostly gravel or sandy material. Capillary effect above the seepage line inside the levee 
was also not considered in the analysis. The distributions of the pore water pressure inside the levee and along the impervious boundary at the bottom of the retaining wall are required for the analysis of retaining wall stability. To perform slope stability analysis coupled with seepage analysis, the software products Slope/W and Seep/W in the GeoStudio suite were employed. Furthermore, the slope safety factor was determined by using Spencer's method.

An illustration of the retaining wall is shown in Fig. 3 (Huang et al., 2014). The forces acting on the retaining wall include the active force from the levee backfill and the passive force from the backfill material on the flood side of the levee. It was assumed that the passive force from the backfill still remains unchanged at the flood side for a less conservative analysis. However, this passive force might decrease when the water level starts to rise with increasing scouring depths. There are also pore water pressures acting on the retaining wall from both sides. As mentioned in the previous paragraph, the uplift force due to the pore water pressure at the bottom of the retaining wall could also reduce the stability of the retaining wall. Therefore, these uplift forces were also considered in the retaining wall sliding and overturning failure analyses.

\subsection{The variability of the parameters}

Three principal parameters were investigated in the stability analyses of the levee: the water levels on the protected side and flood side of the levee, the local scouring depth of the backfill material on the flood side of the levee, and the in situ friction angle along Laonong River. There is some degree of variability in all of these parameters. We now discuss these parameters in more details.

\subsubsection{Water level}

The water level is defined as the height of the water on the flood side from the in situ ground surface, as shown in Fig. 4. There could be a difference between the water levels on the protected and flood sides of the levee, i.e., the water level difference (WLD), due to clogging or drainage problems on either side of the levee. To show that the water level difference may be larger in a long return period flood event, a WLD coefficient was defined as the WLD divided by the water level on the protected side of the levee. The normalization of water level difference to the protected side water level may be more practical for engineers because the protected side water levels of various levee designs might have different values. In this study, the WLD coefficient was assumed to be greater than 0 , which means that the seepage direction is from the protected side of the levee to the flood side. A preliminary analysis showed that this seepage direction is more likely and causes more stability issues for the levee.

The design flood water levels for various flood return periods have been reported by the Water Resources Planning

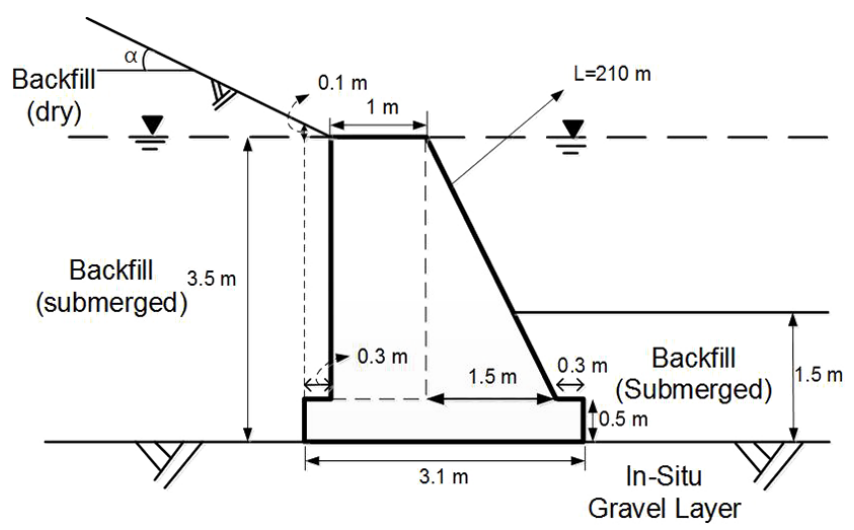

Figure 3. Cross section of the retaining wall of Chiuliao First Levee (Huang et al., 2014).

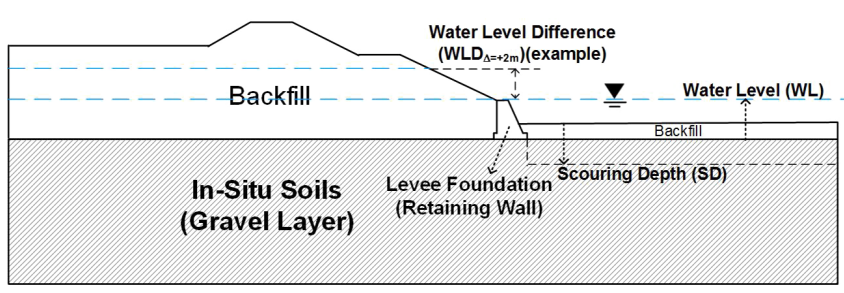

Figure 4. Definitions of the parameters (WLD, WL, and SD) used in levee stability analyses (Huang et al., 2014).

Institute of Taiwan and are shown in Table 2. The design water levels were estimated from the design flow rates in different river sections along the river. Comparing the design water levels for various flood return periods for Laonong River section no. 14 (where Chiuliao First Levee is located), it can be seen that a return period of 200 years results in a water level $(8.5 \mathrm{~m})$ that is approximately $80 \%$ of the height of the levee $(10.7 \mathrm{~m})$. In this study, the water levels corresponding to the various return periods were employed directly in the analysis, with WLD coefficients of $0,0.1,0.2,0.3,0.4$, and 0.5 . Note that these design flow rates for various return periods were obtained before Typhoon Morakot. A newer data set that considers the rainfall record of Typhoon Morakot indicates larger flow rates for the same return period. However, it has been suggested by the Water Resources Planning Institute that the information listed in Table 2 remains valid because there are insufficient flood data to support the newer data set.

\subsubsection{Local scouring depth}

The scouring depth is defined as the depth from the surface of the original backfill on the flood side, as shown in Fig. 4. Huang et al. (2014) demonstrated that the scouring depth is a crucial factor in the stability of levees. However, their results were obtained by assuming particular values for the scouring depth. In this study, the scouring depth was estimated using 
Table 2. Design flow rates and water levels of Chiuliao First Levee for various return periods.

\begin{tabular}{lccc}
\hline $\begin{array}{l}\text { Flood return period } \\
\text { (years) }\end{array}$ & \multicolumn{3}{c}{$\begin{array}{c}\text { Chiuliao First Levee } \\
\text { (River section no. 14) }\end{array}$} \\
\cline { 2 - 4 } & $\begin{array}{c}\text { Flow rate } \\
(\mathrm{cms})\end{array}$ & $\begin{array}{c}\text { Water level } \\
(\mathrm{m})\end{array}$ & $\begin{array}{c}\text { Average SD* } \\
(\mathrm{m})\end{array}$ \\
\hline 200 & 15500 & 8.5 & 1.26 \\
100 & 14200 & 8.24 & 1.23 \\
50 & 12800 & 7.92 & 1.19 \\
20 & 10900 & 7.13 & 1.13 \\
10 & 9370 & 6.72 & 1.07 \\
5 & 7650 & 6.53 & 1.00 \\
2 & 4910 & 4.97 & 0.87 \\
\hline
\end{tabular}

$* \mathrm{SD}=$ scouring depth; $\mathrm{cms}=\mathrm{m}^{3} \mathrm{~s}^{-1}$

an empirical equation by Lacey (1930). As mentioned above, design flow rates and particle sizes are available for the Chiuliao First Levee, and it was found that the empirical equation proposed by Lacey (1930) can be employed to obtain the scouring depth:

$d_{\mathrm{s}}=Z \cdot 0.47 \cdot\left(\frac{Q}{f}\right)^{(1 / 3)}$.

In this equation, $d_{\mathrm{S}}$ is the scouring depth, $Z$ is a factor related to the river bending condition, $Q$ is the design discharge rate in $\mathrm{m}^{3} \mathrm{~s}^{-1}$, and $f$ is Lacey's silt factor, which is related to the mean particle size $\left(D_{\mathrm{m}}\right.$, in $\left.\mathrm{mm}\right)$ of the scoured material as follows:

$f=1.76 \cdot\left(D_{\mathrm{m}}\right)^{(1 / 2)}$.

Lacey's equation can be used to estimate the scouring depths for natural river erosion (classified as Type A) and manmade structures along a bank line (classified as Type B) (Pemberton and Lara, 1984). For a Type B structure, the multiplying factor $Z$ in Lacey's equation is dependent on the river bending condition. For Chiuliao First Levee, the factor $Z$ was assumed to be 0.25 because its length and location correspond to a straight reach condition.

Lacey's equation implies that the design flow rate and the average particle size are the two major parameters governing the scouring depth. The flow rates can be obtained directly from the information in Table 2, whereas the average particle size varies with location along the river. Chiuliao First Levee is located along Laonong River between its confluences with Chokuo and Kaoping Rivers, so soil boring information was collected between these river confluence points. The coefficient of variation (COV) of the average particle size in this river section is approximately $67 \%$. It was assumed that the particle size distribution fits a log-normal distribution with an average particle size of $60.55 \mathrm{~mm}$ and a COV of $67 \%$. The averages of the generated randomized local scouring depths for the various flood return periods are shown in Table 2.

\subsection{In situ friction angle}

As mentioned above, the in situ friction angle is in the range of $37-45^{\circ}$. This friction angle seems reasonable for gravel material, but it exhibits some degree of variability and therefore was treated as a variable in this study for reliability analysis. According to Phoon (2008), the coefficient of variation of the friction angle is between 10 and $15 \%$. In this study, the mean friction angle was assumed to be $40^{\circ}$, with a coefficient of variation of $10 \%$. In addition, the data distribution type was assumed to be log normal.

\section{Analysis results - stability of Chiuliao First Levee}

We examined the slope stability and retaining wall stability under steady state seepage conditions within possible ranges of parameters. The related parameters employed in this study are the water level (and the WLD coefficient), the scouring depth, and the in situ friction angle. As shown in Fig. 5, the water level on the protected side is denoted $h_{1}$, and the water level on the flood side is denoted $h_{2}$. For Chiuliao First Levee, the design backfill thickness on the flood side is $1.5 \mathrm{~m}$, so we analyzed three scouring depths: $0.5,1.0$, and $1.5 \mathrm{~m}$. Levee stability was analyzed in the absence of scouring by Huang et al. (2014). It was found that the safety factor becomes most critical if the water level on the protected side is close to the top of the levee, when a small water level difference can cause slope failure. As shown in Fig. 5 for scouring depths of 0.5 and $1.5 \mathrm{~m}$, it was found that for a scouring depth of about one-third of the backfill material on the flood side (i.e., $\mathrm{SD}=0.5 \mathrm{~m}$ ), the water level has to be close to the top of the levee (which is approximately $10.7 \mathrm{~m}$ ) for the safety factor to decrease (although its values remain greater than 1.0). However, when the scouring depth is $1.5 \mathrm{~m}$ (which indicates that the backfill material has been eroded completely), the safety factor becomes less than 1.0 when the water levels on both sides of the levee are about $6.0 \mathrm{~m}$. This water level is close to three-fifths of the design levee height and is lower than the water level for a flood return period of 200 years.

As shown in Figs. 6 and 7, the retaining wall stability was also analyzed with respect to the sliding and overturning failure for various scouring depths. According to their results for retaining wall stability in the absence of scouring, Huang et al. (2014) found that the corresponding water level has to be close to the top of the levee on the protected side and that a significant water level difference is required for the sliding and overturning safety factor to be less than 1.0. However, as shown in Fig. 6, the retaining wall sliding safety factor decreases as the water level inside the levee increases for scouring depths of 0.5 and $1.5 \mathrm{~m}$, and when the water is close to the top of the levee on the protected side (i.e., $h_{1}$ is large), sliding failure becomes critical. For a scouring depth of $0.5 \mathrm{~m}$, when the water level on the flood side recedes to approximately $6.5 \mathrm{~m}$, sliding failure occurs. When the backfill ma- 

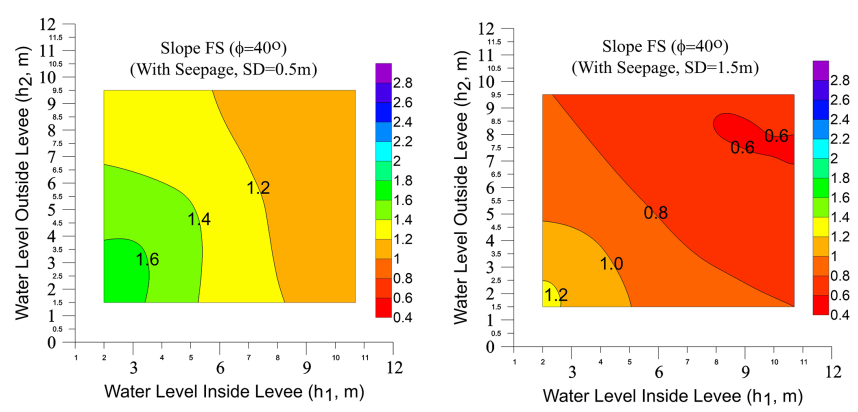

Figure 5. Slope stability of Chiuliao First Levee for SDs of $0.5 \mathrm{~m}$ (left) and $1.5 \mathrm{~m}$ (right).
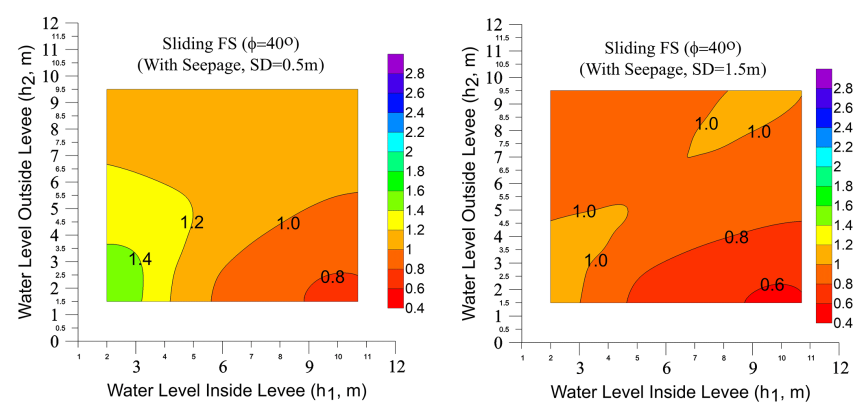

Figure 6. Retaining wall sliding safety factor of Chiuliao First Levee for SDs of $0.5 \mathrm{~m}$ (left) and $1.5 \mathrm{~m}$ (right).

terial on the protected side has been eroded completely (i.e., $\mathrm{SD}=1.5 \mathrm{~m}$ ), the water level on the protected side at which sliding failure occurs is as low as $6.0 \mathrm{~m}$ when the flood side water level is slightly lower than the water level on the other side.

As shown in Fig. 7, the retaining wall overturning safety factor also decreases as the water level increases for scouring depths of 0.5 and $1.5 \mathrm{~m}$, but most of the safety factors are greater than 1.0. Only when the water level on the protected side is at the top of the levee with a significant water level difference does the retaining wall stability became critical (safety factors between 1.0 and 1.2). In short, overturning failure of the retaining wall of the Chiuliao First Levee is unlikely, even when the scouring depth is $1.5 \mathrm{~m}$ (i.e., when the backfill material has been eroded completely).

Based on the above results, we conclude that the failure mechanism of the Chiuliao First Levee could be a combination of slope failure and retaining wall sliding failure. These failure modes could arise in the following scenarios: (1) when there is no local scouring of the flood side backfill material and the water level on the protected side is close to the top of the levee, the sliding failure of the retaining wall can occur once the water has started to recede from the flood side. This result is consistent with the findings of Huang et al. (2014). (2) When there is a small amount of local scouring (such as one-third of the thickness of the backfill material), sliding failure of the retaining wall can occur when the water
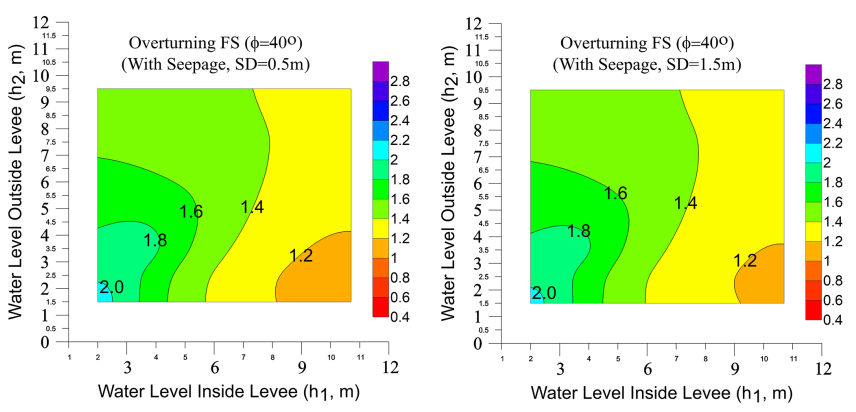

Figure 7. Retaining wall overturning safety factor of Chiuliao First Levee for SDs of $0.5 \mathrm{~m}$ (left) and $1.5 \mathrm{~m}$ (right).

level difference is approximately $4 \mathrm{~m}$. (3) When the backfill layer has been eroded completely (a total thickness of $1.5 \mathrm{~m}$ ), slope failure and retaining wall sliding failure can occur only when the water level is about half of the levee height. Overturning of the retaining wall is unlikely because the critical condition for this type of failure only arises after the other two failure conditions have occurred. Although Figs. 5, 6, and 7 illustrate these possible failure scenarios, some of the required conditions could be unrealistic. For example, (1) a 0 scouring depth might not be possible, especially for a long flood return period and the resulting large flow rate, i.e., a large scouring depth; (2) a certain amount of scouring is possible under a given WLD coefficient, but it is better to treat these parameters as exhibiting significant variability. If the above situations can be considered in the analysis, the results can be closer to actual possible outcomes. With the above considerations in mind, a reliability analysis considering parameter variability was performed and is discussed in the next section.

\section{Reliability analysis for Chiuliao First Levee in southern Taiwan}

\subsection{Reliability analysis method}

In the above analyses, the parameters that could influence the stability of the levee were varied and analyzed based on the failure mechanisms, but in reality these parameters could change with time and location. For example, there are several levees located in different sections of Laonong River, and the corresponding riverbed profiles in these locations are likely to be different. Therefore, the particle sizes (which are related to the scouring depth) and the water levels (which are related to the flood return periods and the WLD coefficient) could also vary from location to location along the river, so it is necessary to consider the effects of this variability.

In this study, the levee's stability with respect to the abovementioned failure mechanisms was analyzed with all possible parameters. These parameters include water levels on the protected and flood sides of the levee, the scouring depths, 
and the in situ friction angles. The water levels of various flood return periods, variation in the WLD coefficient, scouring depths, and in situ friction angles were used to determine the corresponding factor of safety (FS) for a given failure mechanism. A Monte Carlo simulation (MCS) was employed in this study to obtain the distributions of the safety factors for different failure mechanisms. MCS was performed by generating a number of random variables (mean particle sizes and friction angles in this study) that satisfy the required distribution (a log-normal distribution in the current study), from which the corresponding safety factors could be obtained under a given failure mechanism. In this study, MCS was performed 5000 times in order to capture the approximate distribution of the corresponding safety factors within a reasonable analysis time. A trial MCS of 20000 samples showed that the results were similar. The distributions of the safety factor, mean value, standard deviation, and reliability index could be evaluated for each failure mechanism from the analysis results and compared for various flood return periods and WLD coefficients. The reliability index was calculated by using the definition of the safety margin as $M=\mathrm{FS}-1$ and the equation

$\beta=\frac{E[\mathrm{FS}]-1}{\sqrt{\operatorname{Var}[\mathrm{FS}]}}$,

where $\beta$ is the reliability index, $E[\mathrm{FS}]$ is the mean value of the corresponding factor of safety, and $\operatorname{Var}[\mathrm{FS}]$ is its variance. Note that Eq. (3) is valid for a normally distributed factory of safety.

\subsection{Reliability analysis results for Chiuliao First Levee - constant friction angle}

For the results discussed in this section, the friction angle was chosen as $40^{\circ}$, without consideration of its variability. The major purpose was to explore the sensitivity of different failure mechanisms to variations in flood water levels and scouring depths.

The distributions of the safety factor are plotted in Fig. 8 for a flood return period of 100 years and a WLD coefficient of 0.3. The FS distributions of the different failure mechanisms are very distinguishable. Under the above condition, the Chiuliao First Levee experiences slope failure with $100 \%$ probability, whereas the probability of retaining wall sliding failure is approximately $75 \%$ and retaining wall overturning failure is not possible ( $0 \%$ probability). It can also be seen in Fig. 8 that the distribution of the slope failure safety factor is more sensitive to changes in the scouring depth (or the mean particle size because of Lacey's equation) than those of the retaining wall sliding or overturning failures. Slope failure was found to be more sensitive to changes in the scouring depth in all other analyzed cases, i.e., for all flood return periods and WLD coefficients.

When the reliability index is less than 0 , the probability of failure must be greater than $50 \%$. When the distribution of

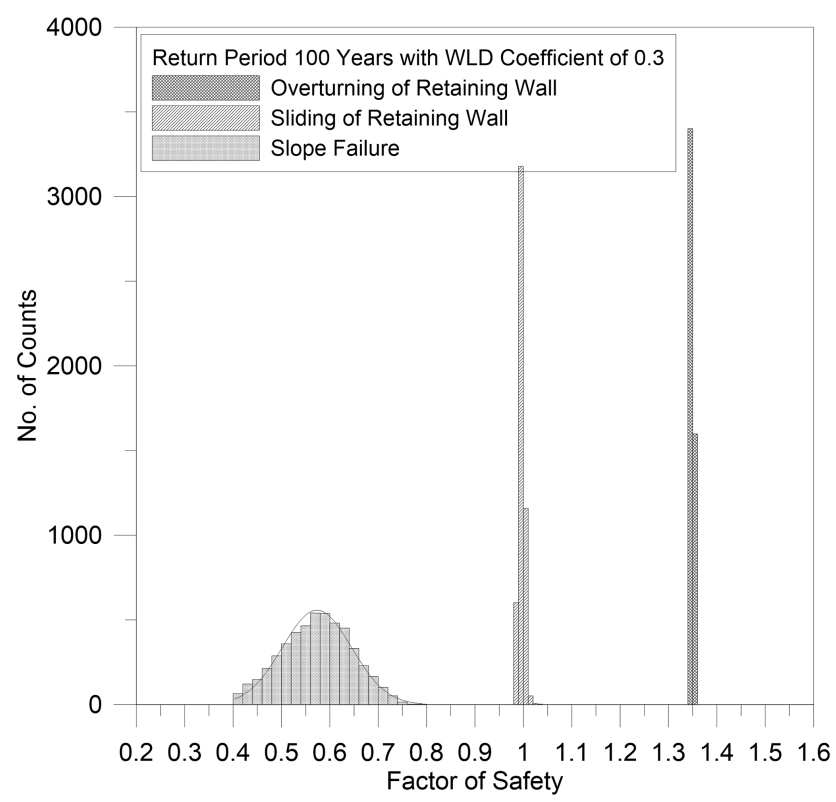

Figure 8. Distributions of safety factors for various failure mechanisms (results shown here are for a flood return period of 100 years and a WLD coefficient of 0.3 ).

the safety factor is similar to a normal distribution, the reliability index can be employed to estimate the corresponding probability of failure (although with a Monte Carlo simulation, the probability of failure related to the analyzed sample numbers can also be obtained). For a normal distribution of the safety factor, a reliability index of 4 represents a failure probability of about $10^{-5}$, which is a commonly accepted probability of failure for most geotechnical facilities. The reliability indices were calculated for Chiuliao First Levee for various flood return periods and WLD coefficients, as shown in Figs. 9 and 10. The variation in the reliability index for retaining wall overturning failure is not shown because it is not possible for Chiuliao First Levee to experience this type of failure when the factors of safety are greater than 1.2 (the minimum reliability index for retaining wall overturning failure is approximately 38 , which is high).

Figure 9 shows the variations in the slope reliability index for various WLD coefficients and return periods. First of all, the reliability indices increase as the flood return period decreases from 200 to 2 years. This increase is due to the corresponding decreases in the water level and the scouring depth: when the flood return period is reduced from 200 to 2 years, the average scouring depth decreases from 1.25 to $0.86 \mathrm{~m}$. However, there are only two situations in which the reliability index is greater than 4 (average FS greater than 1.20): for a flood return period of 2 years and for WLD coefficients of 0.4 and 0.5. It was found that Chiuliao First Levee could undergo slope stability failure even for a design flood return period of only 2 years. In fact, repair and maintenance records for Chiuliao First Levee show that this levee has been 


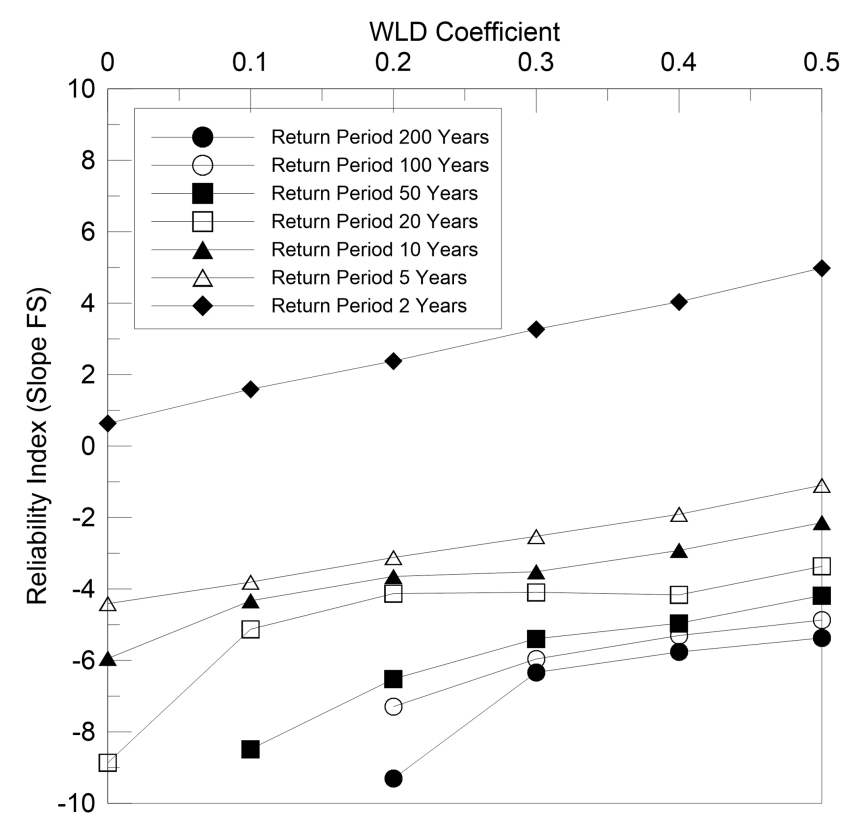

Figure 9. Variations in the slope FS reliability index with the WLD coefficient for various flood return periods.

repaired several times, definitely in 2000 and 2005 and possibly on other occasions.

The variations in the reliability index for retaining wall sliding failure are shown in Fig. 10. It is evident that there are two different trends in the reliability index. The first trend arises when the WLD coefficient is less than 0.25: the longer the flood return period, the larger the reliability index. These reliability indices are greater than 4.0, which corresponds to acceptable probabilities of failure. The other trend arises when the WLD coefficient is larger than 0.25: the longer the flood return period, the smaller the reliability index. Some of the reliability indices are even less than 0 , which is definitely not acceptable for this type of failure. If a reliability index of 4 is considered acceptable, then Chiuliao First Levee is unstable for flood return periods greater than 5 years and WLD coefficients less than 0.25 . For a flood return period of 2 years, the maximum WLD coefficient that the levee can tolerate is close to 0.3. Note also in Fig. 10 that the longer the flood return period, the more sensitive the retaining wall sliding reliability index becomes to the variations in the WLD coefficient. The reliability analysis results show that when the water level is relatively high, only small reductions in the water level result in more substantial decreases in the reliability index than is the case at lower water levels.

\subsection{Reliability analysis results for Chiuliao First Levee - various friction angles}

In the following analysis results, the friction angles and the average particle sizes (or the corresponding scouring depths) were treated as variables with the above-mentioned averages

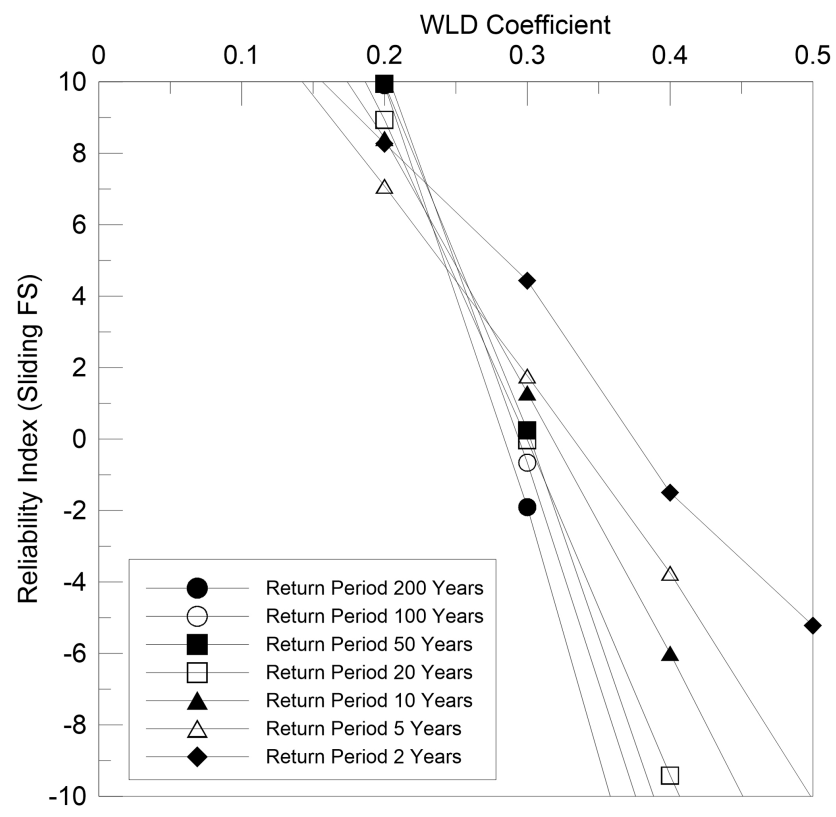

Figure 10. Variations in the retaining wall sliding FS reliability index with the WLD coefficient for various flood return periods.

and coefficients of variation. Log-normal distributions were assumed for both variables.

Figure 11 shows the distributions of the safety factor for slope sliding failure, retaining wall sliding, and overturning failure. The distributions in Fig. 11 are very different to those in Fig. 8. In Fig. 8, when a constant friction angle was employed in the analysis, the variation in scouring depths and water levels affects the shape and location of the slope stability FS distribution only, and the distributions of the retaining wall sliding FS and the overturning FS are close to constant values. When the friction angle is treated as a variable, as shown in Fig. 11, the distribution of the retaining wall FS becomes broader. These results indicate that the slope stability FS is not sensitive to changes in the friction angle because with the variation of friction angles, the slope stability FS distribution is similar to that in Fig. 8. The variation in the slope FS is due mainly to the variation in the scouring depth. The reason for the above results may be the location of the slip circle with respect to the in situ soil layer. Nonetheless, the stability of the retaining wall is not sensitive to changes in the scouring depth, as shown in Fig. 8; however, with the change of friction angles, the distributions of retaining wall FS become different when compared to Fig. 8. Note that these results are for a flood return period of 100 years and a WLD coefficient of 0.3. Other return periods and WLD coefficients also produced similar results.

As mentioned in the previous section, when the variability in the friction angle is taken into account, the slope FS does not change significantly. Figure 12 shows the variations in the slope FS reliability indices and WLD coefficients for various flood return periods; these results are not significantly differ- 


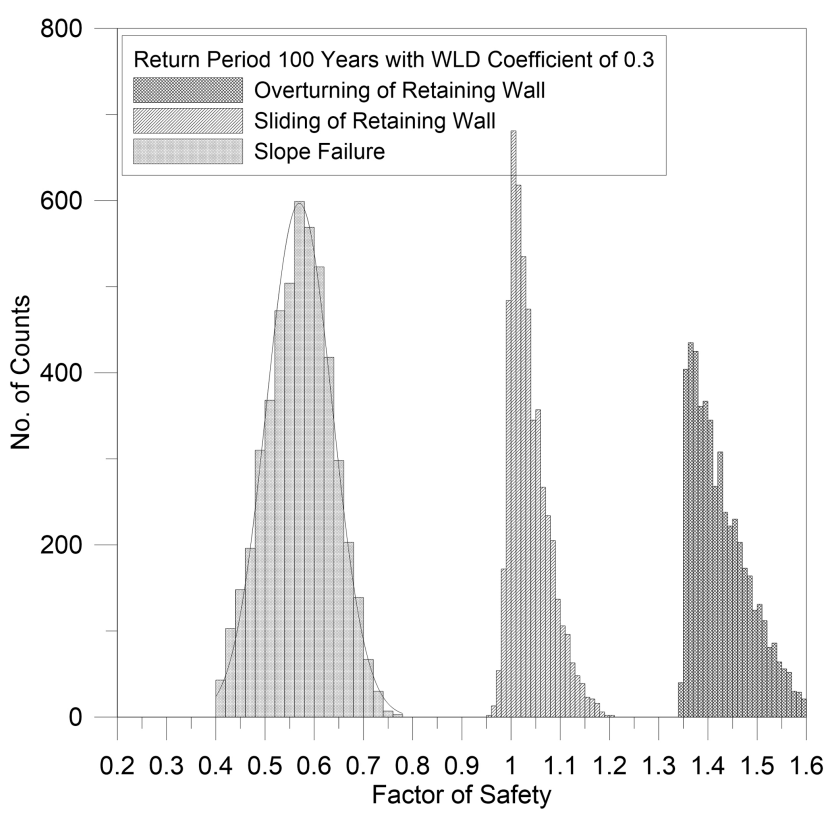

Figure 11. Distributions of the safety factor for various failure mechanisms, with accounting for the variability of the in situ friction angle (results shown here are for a flood return period of 100 years and a WLD coefficient of 0.3 ).

ent from those in Fig. 9. However, the results in Fig. 13 for the retaining wall sliding reliability index and WLD coefficient for various flood return periods are quite different. First of all, the trend in the results for a return period of 2 years is different to that of the other return periods. The reliability index is more sensitive to changes in the WLD coefficient for return periods less than 2 years. For the other flood return periods, there are similar relationships between the reliability index and the WLD coefficient. Although it was shown that the reliability indices are higher for shorter return periods, the reliability index decreases more rapidly with changes in the WLD coefficient for shorter return periods. By considering the variability in the friction angle, it was found that the retaining wall sliding FS of Chiuliao First Levee is less sensitive to changes in the return period. For flood return periods longer than 5 years, the results are similar. The retaining wall overturning FS is not shown because of its high reliability index.

\subsection{Discussion about reliability analysis results for Chiuliao First Levee}

Based on the above reliability analysis about Chiuliao First Levee, the following results can be concluded about the effect of variation of in situ friction angles, water levels, and local scouring depths, as discussed below.

1. If the in situ friction angle is relatively uniform along the levee, the safety factors of levee foundation stability (sliding and overturning) do not vary significantly.

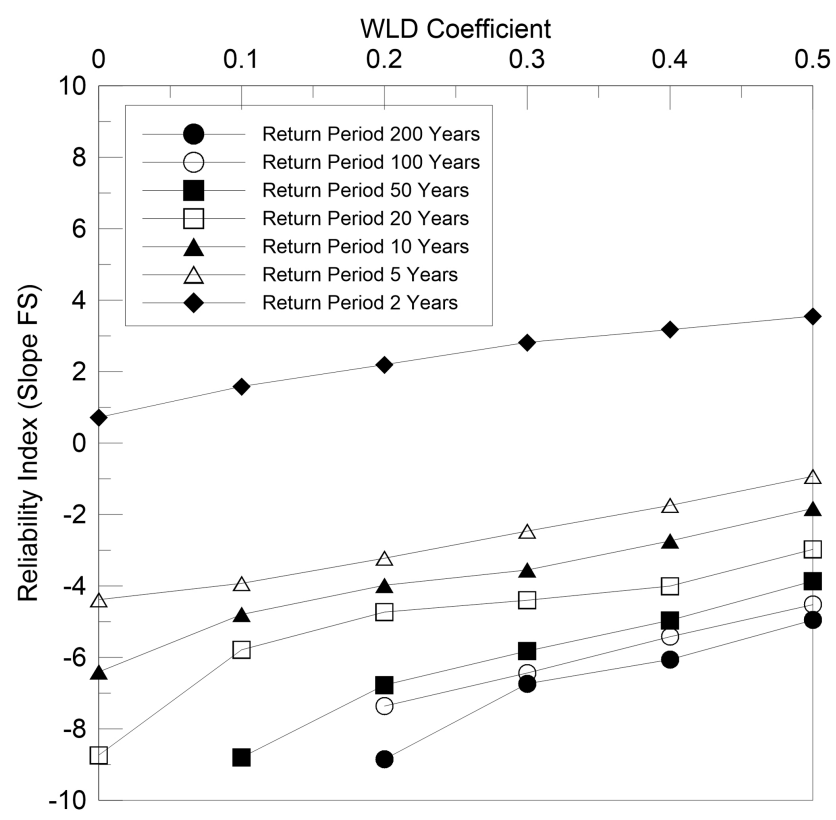

Figure 12. Variations in the slope FS reliability index with the WLD coefficient for various flood return periods, accounting for the variability of the in situ friction angle.

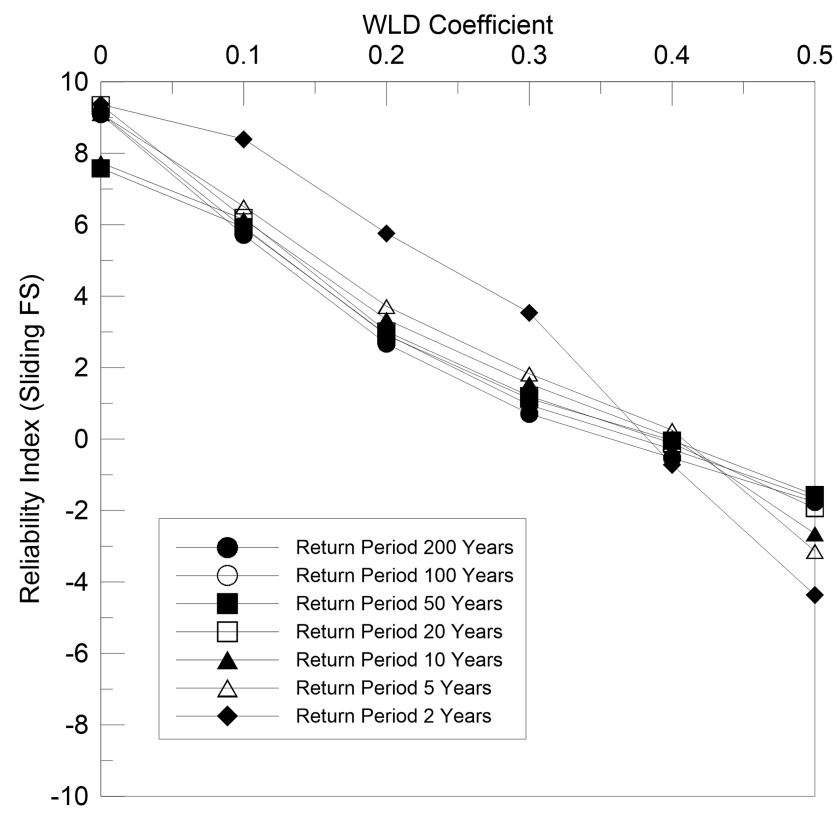

Figure 13. Variations in the retaining wall sliding FS reliability index with the WLD coefficient for various flood return periods, with accounting for the variability of the in situ friction angle.

However, the levee foundation sliding stability is more sensitive to the change of water level difference as the flood return period increases.

2. If the in situ friction angle is various along the levee, the safety factor of levee foundation becomes variable. On 
some occasions, the levee foundation may fail with sliding failure. The levee foundation sliding failure is most sensitive to the water level difference when the flood has a short return period. For flood return periods longer than 5 years, the levee foundation sliding stability may not be a function of WLD coefficient, since the reliability results are similar.

3. The safety factor for slope stability analysis is more affected by the flood return period (which is also related to water level heights and scouring depths) than the in situ friction angle. The reliability indices increase with the increase of WLD coefficient, which means that the combination of various local scouring depths and water levels may yield this kind of variation trend.

With the above discussion, for a design cross section similar to Chiuliao First Levee, the slope sliding failure is the most possible type to occur under all water level heights. However, if the levee is constructed on a relatively uniform (in terms of strength parameters) soil layer, the water level difference between protected and flood side of levee (WLD coefficient between 0.25 and 0.3 ) should be paid more attention when a long return period flood occurs, under which circumstance the levee foundation may undergo sliding failure. However, if the levee is constructed on less uniform (in terms of strength parameters) soil layers, the water level difference may be more influential on the change of reliability indices for levee foundation sliding stability with a short flood return period. The reliability indices are similar (and low) with flood return periods greater than 5 years. Under this circumstance, WLD coefficient between 0.2 and 0.3 may result in levee foundation sliding failure.

\section{Conclusions}

In recent years, heavy rainfall conditions have caused the loss of numerous human lives and properties around the world. To reduce the damages by floods, levees were constructed in the low-rise or inundation-prone areas. If the design of the levees did not consider the effects of extreme rainfall through various failure mechanisms, levee failures could occur, such as those during Hurricane Katrina in the USA in 2005 and Typhoon Morakot in southern Taiwan in 2009. The rainfall record in southern Taiwan during Typhoon Morakot was even close to the world record. This study performed a reliability analysis of Chiuliao First Levee in southern Taiwan. The reliability of the Chiuliao First Levee on Laonong River with respect to various possible failure mechanisms was analyzed. The parameters employed in this study were the water level and the scouring depth, which are related to the flood return period, and the in situ friction angle. Three major failure mechanisms were considered, including slope failure of the levee and sliding and overturning failures of the retaining wall. The possible difference between the water levels on the two sides of the levee was accounted for by including water level difference (WLD) coefficients in the above analysis and a steady state seepage condition inside the levee.

On the one hand, our results show that retaining wall sliding and overturning failures are less sensitive to variation in the scouring depth than slope sliding failure when a constant value of the friction angle is considered. In addition, we found that the longer the flood return period, the more sensitive the retaining wall sliding reliability index becomes to variation in the WLD coefficient. On the other hand, when the variability of the in situ friction angle and scouring depth were included in the analysis for various flood return periods, it was found that retaining wall sliding and overturning failures are more sensitive to variability in the friction angle. The results for the distribution of the slope sliding failure FS obtained when accounting for the variability in the in situ friction angle are similar to those obtained with constant in situ friction angles. This shows that slope sliding is less sensitive to variability in the friction angle.

Our comprehensive stability and reliability analysis of Chiuliao First Levee, which takes into account parameter variability, has shown that the levee could fail through slope sliding (for all WLD coefficients) and retaining wall sliding failure (for high WLD coefficients) for a flood return period of 200 years, which corresponds to a flow rate lower than that arising during Typhoon Morakot. The stability of Chiuliao First Levee can be divided into two regimes depending on the flood return period. When the flood return period is less than or equal to 2 years, Chiuliao First Levee is not stable with respect to retaining wall sliding failure when there is a large WLD coefficient (greater than 0.4). When the flood return period is greater than 2 years, slope sliding failure of the levee can occur for all values of the water level difference. These failures arise because of the large scouring depths (greater than $1.0 \mathrm{~m}$ ) of longer flood return periods. Retaining wall sliding failures occur for only moderate to large values of the WLD coefficient (greater than 0.25). Based on the above failure mechanisms for Chiuliao First Levee, the corresponding countermeasures can thus be taken during repair or maintenance of the levees. For example, in the renovation report of Chiuliao First Levee, rows of piles and thickened backfill material were added into the design cross section without increasing the design height of the levee. The above engineering treatment methods can indeed increase the stability against slope sliding and retaining wall sliding, which are the two major failure mechanisms under different flood return periods concluded in this study. For general levee analyses, it is suggested to consider the stability of the levees from different flood return periods, because the levee failure mechanisms might be different.

In the past, it was common to adopt a general design cross section for the whole length of a levee, especially local levees in suburban areas (mainly because of low cost for construction and maintenance). However, the water level during rainfall events might vary at different locations on the river, 
indicating that an identical levee design cross section along the levee may not satisfy various water heights when flood occurs. Furthermore, if the design or analysis does not consider the effects of heavy rainfall events and various failure mechanisms, unexpected failures of the levee could occur, as in the case discussed in this study. Although only three major failure mechanisms were selected for analysis in this study (based on previous site investigation reports and interviews with local residents), it is crucial for the design of other levees to consider possible failure mechanisms, especially under heavy rainfall conditions. In addition, the uncertainties of the parameters were also taken into account with reliability analysis in this study, as a response to the recommendations proposed by Sills et al. (2008) under extreme weather conditions such as Hurricane Katrina. The sensitivity of the levee stability with respect to the relevant parameters can thus be examined with the variations of reliability indices.

Based on the reliability analysis for Chiuliao First Levee, if one needs to re-examine the current levee stability due to floods caused under extreme rainfall, it is suggested to take the following approaches to understand possible failure mechanisms:

1. Collect levee repair or maintenance reports; if there are eyewitness reports when the levee failed, it is very crucial for the following analysis.

2. Collect levee design cross sections and any nearby soil boring information.

3. Obtain hydrology analysis and design flow rate reports for the river on which the analyzed levee is located and find out the corresponding water levels at that specific river section under different design flood return periods.

4. Select possible failure mechanisms; as mentioned previously, any repair, maintenance, or eyewitness reports are crucial in properly determining the failure mechanisms.

5. Choose proper parameters for parametric study; based on the analysis results in this study, the local scouring depths, water levels (at both sides of the levee), and in situ friction angles are considered as crucial factors in different failure mechanisms.

6. Assume proper distributions for the above parameters; for geotechnical properties, it is common to assume a log-normal distribution for reliability analysis.

7. Perform comprehensive stability analysis for different failure mechanisms.

8. Perform Monte Carlo Simulation for reliability analysis.

The results can thus be analyzed and examined to see the possible failure mechanisms. Although the above analysis approaches might increase the cost in the design and construction of levees, to reduce the levee failures during the extreme rainfall condition (which is becoming more and more frequent) the comprehensive analysis costs may be comparable with the repair and renovation costs after the disaster occurs. Failures of levees under the influence of extreme weather conditions may thus be prevented by designing with possible failure mechanisms in mind, and the loss of human lives and properties could be minimized.

Acknowledgements. The authors would like to express their sincere thanks for the support by the Ministry of Science and Technology, Taiwan (previously the National Science Council of Taiwan; grant no. NSC101-2218-E-002-001) and Water Resources Agency of Taiwan. The reviewing comments by the reviewers are also greatly appreciated.

Edited by: H. Kreibich

Reviewed by: two anonymous referees

\section{References}

Brandon, T., Wright, S., and Duncan, J.: Analysis of the stability of I-Walls with gaps between the I-Wall and the levee fill, J. Geotech. Geoenviron., 134, 692-700, 2008.

Briaud, J., Chen, H., Govindasamy, A., and Storesund, R.: Levee erosion by overtopping in New Orleans during the Katrina Hurricane, J. Geotech. Geoenviron., 134, 618-632, 2008.

Chang, L. P.: The Disaster Investigation and Improvement Measures of Hydraulic Facilities after Typhoon Morakot. Risk Assessment for Geotechnical Facilities under Extreme Events, Department of Civil Engineering, National Taiwan University, Taipei, Taiwan, 2012.

Dos Santos, R. N. C., Caldeira, L. M. M. S., and Serra, J. P. B. FMEA of a tailings dam, Georisk, 6, 89-104, 2011.

Dou, S.-T., Wang, D.-W., Yu, M.-H., and Liang, Y.-J.: Numerical modeling of the lateral widening of levee breach by overtopping in a flume with $180^{\circ}$ bend, Nat. Hazards Earth Syst. Sci., 14, 11-20, doi:10.5194/nhess-14-11-2014, 2014.

Duncan, J., Brandon, T., Wright, S., and Vroman, N.: Stability of I-Walls in New Orleans during Hurricane Katrina, J. Geotech. Geoenviron., 134, 681-691, 2008.

El Shamy, U. and Aydin, F.: Multiscale modeling of flood-induced piping in river levees, J. Geotech. Geoenviron., 134, 1385-1398, 2008.

Huang, W.-C., Weng, M.-C., and Chen, R.-K.: Levee failure mechanisms during the extreme rainfall event: a case study in Southern Taiwan, Nat. Hazards, 70, 1287-1307, 2014.

IPET - Interagency Performance Evaluation Task Force, I: Performance evaluation of the New Orleans and Southeast Louisiana Hurricane protection system, Final Rep. of the Interagency Performance Evaluation Task Force, US Army Corps of Engineers, USA, 2007.

Lacey, G.: Stable Channels in Alluvium, in: Proceedings, Institution of Civil Engineers, London, England, 229, 259-384, 1930.

Li, W. S., Yeh, K. C., Lin, C. C., Shieh, C. L., Wen, J. C., Yeh, Y. L., Hsieh, L. S., Chen, L. Q., Li, H. C., and Wang, Y. W.: Disaster survey and analysis of Morakot Typhoon, Taipei, Taiwan, National Science Council, Taiwan, 2009. 
Lin, C. W., Chang, W. S., Liu, S. H., Tsai, T. T., Lee, S. P., Tsang, Y. C., Shieh, C. L., and Tseng, C. M.: Landslides triggered by the 7 August 2009 Typhoon Morakot in Southern Taiwan, Eng. Geol., 123, 3-12, 2011.

Liu, C. B., Tsai, W. H., Heish, K. J., Lin, C. H., and Chang, D. C.: Survey and improvement measures on Southern Taiwan hydraulic facilities after 88 Flood, Sino-Geotechnics, 122, 95104, 2009.

Ojha, C., Singh, V., and Adrian, D.: Influence of porosity on piping models of levee failure, J. Geotech. Geoenviron., 127, 10711074, 2001.

Pemberton, E. L. and Lara, J. M.: Computing Degradation and Local Scour - Technical Guideline for Bureau of Reclamation, Sedimentation and River Hydraulics Section, Hydrology Branch, Division of Planning Technical Services, Engineering and Research Center, Denver, CO, USA, 1984.

Phoon, K.-K.: Reliability-based design in geotechnical engineering: computations and applications, CRC Press, London, UK, 2008.

Polemio, M. and Lollino, P.: Failure of infrastructure embankments induced by flooding and seepage: a neglected source of hazard, Nat. Hazards Earth Syst. Sci., 11, 3383-3396, doi:10.5194/nhess-11-3383-2011, 2011.

Riegger, T., Bieberstein, A., Hörtkorn, F., and Kempfert, H.-G.: Stabilisation of river dykes with drainage elements, Nat. Hazards Earth Syst. Sci., 9, 2039-2047, doi:10.5194/nhess-9-2039-2009, 2009.

Seed, R. B., Bea, R. G., Abdelmalak, R. I., Athanasopoulos-Zekkos, A., Boutwell, G. P., Briaud, J. L., Cheung, C., Cobos-Roa, D., Ehrensing, L., Govindasamy, A. V., Harder, J. L. F., Inkabi, K. S., Nicks, J., Pestana, J. M., Porter, J., Rhee, K., Riemer, M. F., Rogers, J. D., Storesund, R., Vera-Grunauer, X., and Wartman, J.: New Orleans and Hurricane Katrina, I: Introduction, Overview, and the East Flank, J. Geotech. Geoenviron., 134, 701-717, 2008a.
Seed, R. B., Bea, R. G., Athanasopoulos-Zekkos, A., Boutwell, G. P., Bray, J. D., Cheung, C., Cobos-Roa, D., Cohen-Waeber, J., Collins, B. D., Harder, J. L. F., Kayen, R. E., Pestana, J. M., Riemer, M. F., Rogers, J. D., Storesund, R., Vera-Grunauer, X., and Wartman, J.: New Orleans and Hurricane Katrina. IV: Orleans East Bank (Metro) protected basin, J. Geotech. Geoenviron., 134, 762-779, 2008b.

Sills, G., Vroman, N., Wahl, R., and Schwanz, N.: Overview of New Orleans Levee Failures: Lessons Learned and Their Impact on National Levee Design and Assessment, J. Geotech. Geoenviron. Eng., 134, SPECIAL ISSUE: Performance of Geo-Systems during Hurricane Katrina, 556-565, 2008.

van Gelder, P., Buijs, F., Horst, W., Kanning, W., Mai Van, C., Rajabalinejad, M., de Boer, E., Gupta, S., Shams, R., van Erp, N., Gouldby, B. P., Kingston, G., Sayers, P. B., Willis, M., Kortenhaus, A., and Lambrecht, H. J.: Reliability analysis of flood defence structures and systems in Europe, FLOODrisk 2008, Keble College, Oxford, UK, 2008.

Vrijling, J. K., Schweckendiek, T., and Kanning, W.: Safety standards of flood defenses, ISGSR 2011, Bundesanstalt für Wasserbau, Munich, Germany, 2011.

Weng, M. C., Wu, M. H., Ning, S. K., and Jou, Y. W.: Evaluating triggering and causative factors of landslides in Lawnon River Basin, Eng. Geol., 123, 72-82, 2011.

Wu, C. H., Chen, S. C., and Chou, H. T.: Geomorphologic characteristics of catastrophic landslides during typhoon Morakot in the Kaoping Watershed, Taiwan, Eng. Geol., 123, 13-21, 2011.

$\mathrm{Xu}$, Y., Li, L., and Amini, F.: Slope stability analysis of earthen levee strengthened by high performance turf reinforcement mat under hurricane overtopping flow conditions, Geotechnical and Geological Engineering, 30, 893-905, 2012.

Zhang, L. M., Xu, Y., Liu, Y., and Peng, M.: Assessment of flood risks in Pearl River Delta due to levee breaching, Georisk, 7, 122-133, 2013. 